\title{
GEOCRONOLOGIA Rb-Sr DA PORÇÃO SUDOESTE DO MACIÇO DE GOIÁS
}

\author{
MÁRCIO M. PIMENTEL \& REINHARDT A. FUCK*
}

\begin{abstract}
Rb-Sr GEOCHRONOLOGY OF THE SOUTHWESTERN GOIÁS MASSIF. Five orthogneissic and metavolcanic rock units and eight undeformed to slightly deformed granitic intrusions from the southwestern portion of the Goiás Massif, western Goiás, were analyzed by the Rb-Sr whole-rock isochron method. Ali rock units investigated yielded Neoproterozoic to early palaeozoic ages (ca. 940 to $485 \mathrm{Ma}$ ). Initial ${ }^{87} \mathrm{Sr} r^{86} \mathrm{Sr}$ ratios for the metamorphic rock units are low, mostly between $c a .0 .702$ and 0.705 . These data provide further evidence for an important Neoproterozoic crustal accretion event in central Brazil, already reported in previous papers. Initial ${ }^{87} \mathrm{Sr}{ }^{86} \mathrm{Sr}$ for the granitic intrusions are more varied, between $c a .0 .703$ and 0.710 and seem to indicate mantle as well as crustal contributions to the parental magmas.
\end{abstract}

Keywords: Goiás Massif, Rb-Sr Geochronology, Neoproterozoic, Brasiliano Cycle.

RESUMO Cinco suítes de rochas metamórficas (ortognaisses e metavulcânicas) e oito intrusões graníticas levemente deformadas a não-deformadas, expostas na porção sudoeste do Maciço de Goiás, foram analisadas pelo método isocrônico $\mathrm{Rb}-\mathrm{Sr}$, em amostras de rocha-total. Todas as unidades investigadas forneceram idades neoproterozóicas a eopaleozóicas (ca. 940 a $485 \mathrm{Ma}$ ). As razões ${ }^{87} \mathrm{Sr}{ }^{86} \mathrm{Sr}$ iniciais das unidades ortognáissicas e metavulcânicas são, de modo geral, baixas (entre $c a$. 0,702 e 0,705). Esses dados suportam a existência de um importante evento de formação de rochas a partir do manto, na região central do Brasil durante o Neoproterozóico. As razões ${ }^{87} \mathrm{Sr}{ }^{86} \mathrm{Sr}$ iniciais, obtidas para as intrusões graníticas, variam dentro de uma faixa mais ampla de valores, entre $c a$. 0,703 e 0,710 , sugerindo contribuições mantélicas e crustais na formação dos magmas originais.

Palavras-chave: Maciço de Goiás, Geocronologia Rb-Sr, Neoproterozóico, Ciclo Brasiliano.

INTRODUÇÃO Os terrenos Pré-Cambrianos, que constituem a Província Tocantins, na porção central do Brasil, são caracterizados por faixas supracrustais dobradas e metamorfizadas, expostas ao longo das bordas dos Crátons Amazônico (Faixas Paraguai e Araguaia) e do São Francisco (Faixas Brasília e Uruaçu) (Fig. 1). Em meio às faixas dobradas, encontra-se o chamado Maciço de Goiás, um maciço de rochas cristalinas de natureza e idade variadas (Fuck et al. 1987), cujo significado geotectônico é ainda mal entendido em função da escassez de dados geocronológicos, geofísicos e estruturais. Marini et al. (1984) interpretam o maciço como um alto estrutural do embasamento siálico das faixas dobradas, enquanto Fuck et al. (1987) e Pimentel (1991) referem-se a ele como um mosaico de blocos, compreendendo terrenos de idade arqueana, bem como áreas neoproterozóicas formadas em ambientes de arco magmático.

Neste trabalho, estão apresentados e discutidos resultados geocronológicos inéditos obtidos pelo método $\mathrm{Rb}-\mathrm{Sr}$ em um conjunto de rochas graníticas, gnáissicas e metavulcânicas da região sudoeste do Maciço de Goiás. O estudo teve como objetivo identificar os eventos de formação de rochas ígneas e metamórficas naquela porção do maciço, de forma a contribuir para o melhor entendimento do seu significado geotectônico.

GEOLOGIA DO OESTE DE GOIÁS Nos terrenos pré-cambrianos da região oeste de Goiás, estão expostas diversas suítes de rochas metavulcânicas e ortognáissicas que constituem o embasamento metamórfico na região. Essas unidades são justapostas através de importantes zonas de cisalhamento do tipo strike slip, de direção NNE a NNW, e mergulhos verticais, tais como o lineamento Fazenda Nova (Fig. 2). Quatro tipos de associações litológicas constituem os componentes principais do embasamento metamórfico no sudoeste de Goiás:

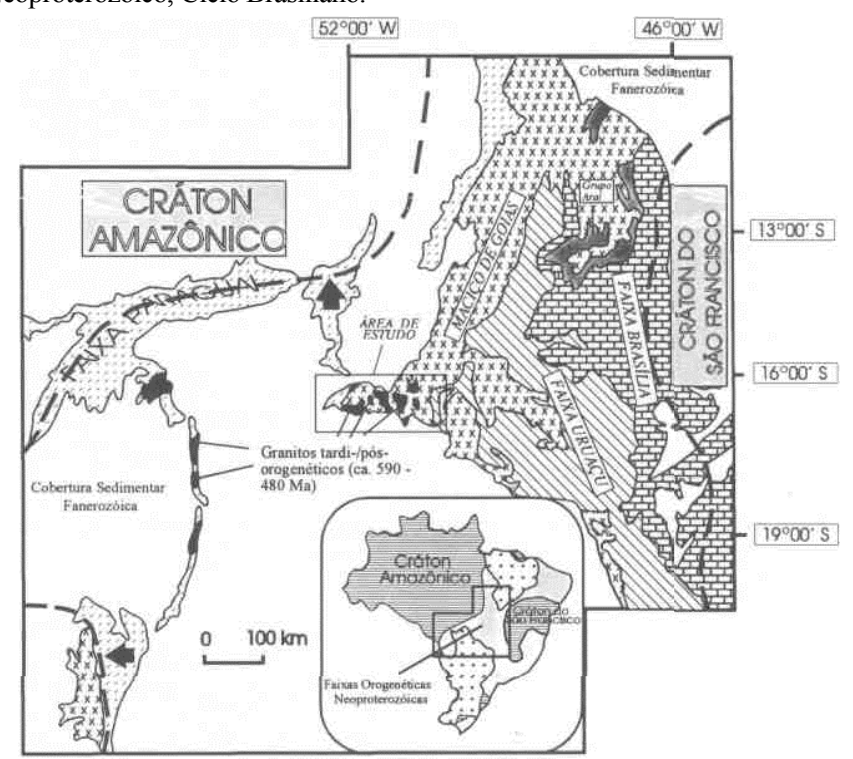

Figura 1 - Mapa geológico esquemático da Província Tocantins, mostrando a área do presente estudo

Figure 1 - Geologic sketch map of the Tocantins Province, indicating the study área

(i) Ortognaisses cálcicos a cálcio-alcalinos homogéneos, portadores de hornblenda e biotita (e.g. gnaisses de Arenópolis, Matrinxã e Sanclerlândia). Texturas e estruturas ígneas preservadas são raras nessas rochas; no entanto, feições, tais como enclaves máficos deformados, pequenos diques leucocráticos tardios e texturas porfiríticas reliquiares, são observadas localmente e atestam a natureza plutônica dos protolitos. Pimentel et al. (1991) reportam 
idade U-Pb em zircões de $899 \pm 7 \mathrm{Ma}$, para a cristalização das rochas intrusivas originais do gnaisse de Arenópolis; (ii) Sequências metavulcânicas/metassedimentares semelhantes às de arcos de ilhas (e.g. Bom Jardim de Goiás, Arenópolis, Iporá, Jaupaci) são constituídas por metabasaltos toleíticos de baixo-K, metabasaltos cálcio-alcalinos, metandesitos, metadacitos e metarriolitos (Seer 1985, Pimentel \& Fuck 1986, 1987b, Amaro 1989). Pimentel et al. (1991) reportam idades U-Pb em zircões de $929 \pm 8 \mathrm{Ma}$ e $764 \pm 14 \mathrm{Ma}$, para rochas metarriolíticas das Sequências de Arenópolis e Jaupaci, respectivamente. Metarriolitos milonitizados da Sequência de Jaupaci apresentam idade isocrônica de $594 \pm 37 \mathrm{Ma}\left(\mathrm{R}_{0}=0,7051 \pm 0,0006\right.$, Pimentel et al. 1991). Idade $\mathrm{Rb}-\mathrm{Sr}$ semelhante $(600 \pm 31 \mathrm{Ma}$, $\left.\mathrm{R}_{0}=0,7036 \pm 0,0048\right)$ foi apresentada pêlos mesmos autores para metarriolitos milonitizados expostos ao longo do Lineamento Fazenda Nova, nas proximidades da cidade de
Fazenda Nova (Fig. 2). Ambas as idades são interpretadas como o registro da época de recristalização metamórfica dessas rochas;

(iii) Sequências predominantemente metapelíticas, contendo micaxistos com granada, estaurolita, cianita e sillimanita, mármores impuros, metacherts e anfibolitos, bem como corpos máfico-ultramáficos de variadas dimensões, foram interpretadas por Pimentel \& Fuck (1987b) como pequenos remanescentes de complexos ofiolíticos fortemente deformados e desmembrados. Duas ocorrências principais de corpos dessa natureza são observadas na região, indicando a possível existência de ao menos duas zonas de sutura de bacias oceânicas estreitas, entre arcos de ilhas (Fig. 2); (iv) Granitos milonitizados, formando corpos estreitos e alongados, tais como o Granito da Serra do Tatu. A foliação milonítica é normalmente vertical e fortemente desenvolvida ao longo dos contatos entre o granito e unidades vizinhas.
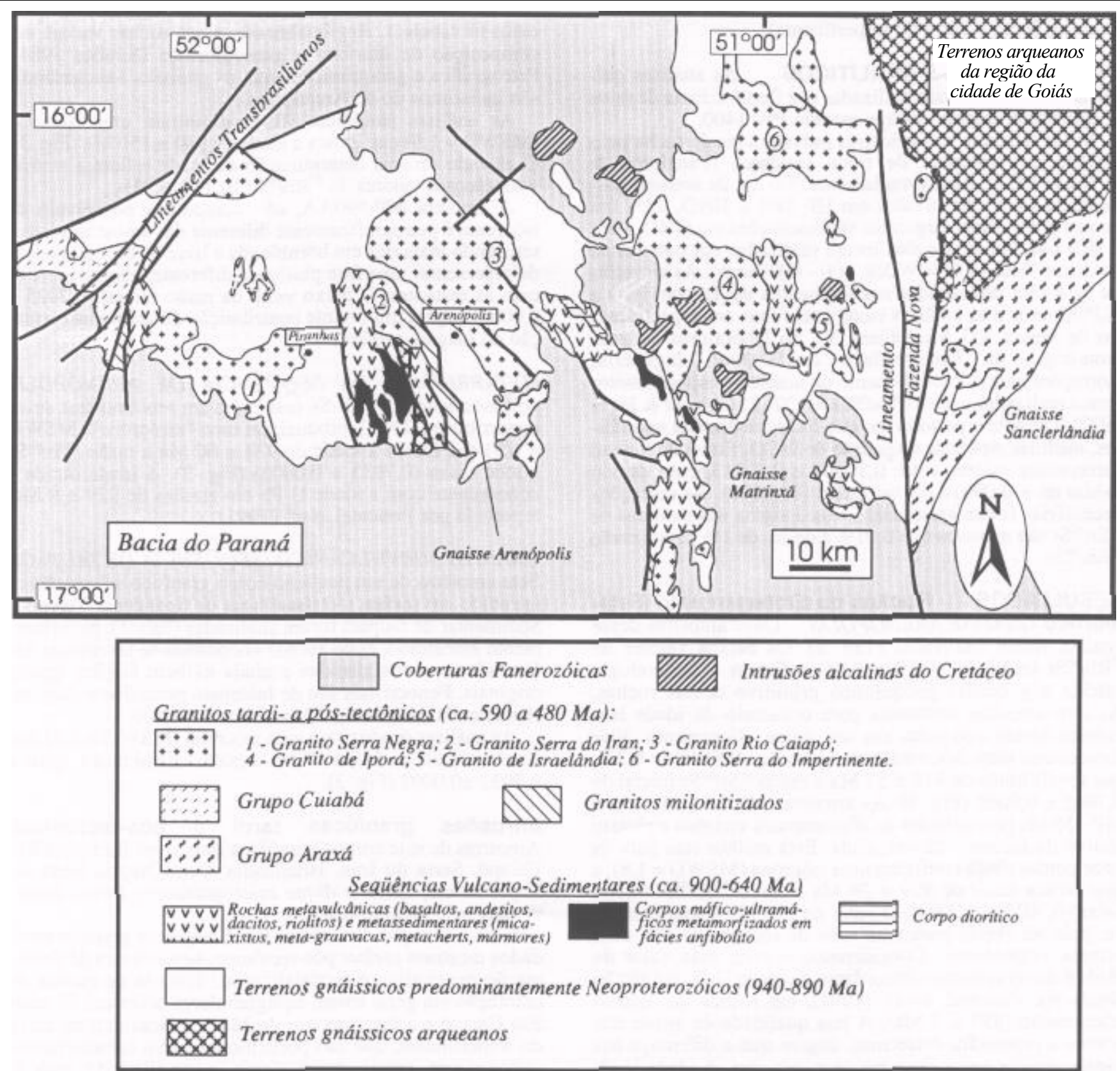

Figura 2 -Mapa geológico esquemático da região oeste de Goiás. Veja figura 1 para localização

Figure 2 - Geologic sketch map of western Goiás. See figure 1 for locations 
Os dados geocronológicos preliminares pelo método $\mathrm{U}-\mathrm{Pb}$, bem como dados geoquímicos e de isotopos de $\mathrm{Nd}$ disponíveis na literatura, indicam que parte substancial das unidades metaígneas que constituem o embasamento metamórfico no sudoeste de Goiás tiveram seus protolitos magmáticos adicionados à crosta continental, em ambiente de arco magmático, durante o Neoproterozóico (Pimentel et ai. 1991, Pimentel \& Fuck 1991,1992). Os valores positivos de $e_{\mathrm{Nd}}$ (entre $+2,5$ e $+6,9$ ), registrados para essas rochas, indicam a presença de componente fortemente depletado no manto-fonte dos magmas originais (Pimentel \& Fuck 1992).

As rochas ortognáissicas e sequências vulcano-sedimentares são intrudidas por vários corpos graníticos tardi- a pós-tectônicos, alojados durante os estágios finais de evolução do Ciclo Brasiliano na região (ca. 590 e 480 Ma; Pimentel et al. 1985, Pimentel \& Fuck 1987a). Trata-se de corpos graníticos de grandes dimensões, que variam desde intrusões do tipo I-Caledoniano (e.g. Granitos Rio Caiapó e Serra do Iran, Fig. 2) ao tipo A (e.g. fases tardias dos Granitos Iporá e Serra do Impertinente).

PROCEDIMENTOS ANALÍTICOS As análises químicas de $\mathrm{Rb}$ e $\mathrm{Sr}$ foram realizadas por fluorescência de raios X em espectrômetro Phillips modelo PW 1400.

$\mathrm{Sr}$ foi separado das amostras pulverizadas de rocha pelo método convencional de troca cationica (Pankhurst \& O'Nions 1973). Aproximadamente $200 \mathrm{mg}$ de amostra pulverizada foram dissolvidos em $\mathrm{HF} 48 \%$ e $\mathrm{HNO}_{3} 16 \mathrm{M}$ em bequeres de teflon. Seguiram-se dissoluções em $\mathrm{HNO}_{3} 16 \mathrm{M}$ e $\mathrm{HCl} 6 \mathrm{M}$. As separações foram realizadas em colunas de troca catiônica (AG 50W X8, 200 - 400 mesh). As amostras de $\mathrm{Sr}$ foram depositadas em filamentos de $\mathrm{Ta}$ com $\mathrm{H}_{2} \mathrm{O}$ e $\mathrm{H}_{3} \mathrm{PO}_{4}$ puros e as análises isotópicas feitas em espectrômetro de massa VG Micromass 30, no laboratório de geocronologia da Universidade de Oxford, Inglaterra. Correções para o fracionamento de massa no espectrômetro foram realizadas usando ${ }^{88} \mathrm{Sr}{ }^{86} \mathrm{Sr}=8,37521$ (Steiger \& Jàger 1977). Durante o período em que foram realizadas as análises, medidas repetidas do padrão de $\mathrm{SrCO}_{3}$ Eimer \& Amend forneceram valores entre 0,70807 e 0.70813 , com desvio médio de $+0,00010$ do valor real $(0,70800)$. As correções necessárias foram aplicadas. Erros 2 sigma nas medidas de ${ }^{87} \mathrm{Sr} /{ }^{86} \mathrm{Sr}$ são menores que $0,01 \%$ e de $c a$. de $1 \%$ para a razão ${ }^{87} \mathrm{Rb} /{ }^{86} \mathrm{Sr}$.

RESULTADOS Rochas do Embasamento Metamórfico GNAISSE ARENOPOLIS Onze amostras desse gnaisse foram analisadas (Tab. 1). Os baixos valores de ${ }^{8 /} \mathrm{Rb} /{ }^{86} \mathrm{Sr}$ (entre $c a .0,10$ a 0,84 ) refletem a mineralogia cálcica e o caráter geoquímico primitivo dessas rochas. As oito amostras utilizadas para o cálculo da idade isocrônica foram coletadas em um único afloramento. Elas forneceram uma isócrona bem ajustada (MSWD $=0,33$ ), que revela idade de $818 \pm 57 \mathrm{Ma}$ e razão "Sr/^Sr inicial de $0,7042 \pm 0,0005$ (Fig. 3). As amostras MP-154, MP-155 e MP-558 são provenientes de afloramentos vizinhos e plotam abaixo da melhor reta calculada. Esta melhor reta para os onze pontos ainda configura uma isócrona (MSWD $=1,8)$, a qual indica idade de $909 \pm 29 \mathrm{Ma}$ e razão ${ }^{87} \mathrm{Sr} /{ }^{86} \mathrm{Sr}$ inicial baixa $(0,7033 \pm 0,0002)$. O valor de $818 \mathrm{Ma}$ é aqui preferido, pois foi obtido para uma suíte de rochas que são, com certeza, cogenéticas. Considerando o erro, esse valor de idade é marginalmente discordante da idade U-Pb em zircão obtida por Pimentel et al. (1991), em rochas do mesmo afloramento $(899 \pm 7 \mathrm{Ma})$. A boa qualidade do ajuste dos pontos à regressão, entretanto, sugere que a diferença nas idades obtidas pêlos dois métodos seja real. A idade U-Pb reflete a cristalização do protolito plutônico, enquanto a isócrona $\mathrm{Rb}-\mathrm{Sr}$ registra a época de fechamento final do sistema isotópico $\mathrm{Rb}$ - $\mathrm{Sr}$, provavelmente após prolongado período de resfriamento do protolito, a profundidades consideráveis na crosta continental. Alternativamente, é possível que a idade isocrônica $\mathrm{Rb}-\mathrm{Sr}$ de ca. $818 \mathrm{Ma}$ esteja refletindo re-homogeneização isotópica do sistema $\mathrm{Rb}$-Sr, devido a uma fase metamórfica daquela idade.

GNAISSE MATRINXÃ Oito amostras desse ortognaisse portador de biotita foram investigadas (Tab. 1). As amostras revelaram uma faixa muito estreita de variação da razão ${ }^{87} \mathrm{Rb}{ }^{86} \mathrm{Sr}(0,08$ a 0,23$)$, o que resultou, juntamente com a considerável dispersão dos pontos analíticos da melhor reta $(\mathrm{MSWD}=12$ ), no grande valor do erro na determinação da idade $\left(895 \pm 290 \mathrm{Ma}\right.$, Fig. 3). A razão ${ }^{87} \mathrm{Sr}{ }^{86} \mathrm{Sr}$ inicial é bastante baixa $(0,7026 \pm 0,0007)$ e compatível com uma curta história crustal prévia dos precursores do Gnaisse Matrinxã.

GNAISSE SANCLERLANDIA Resultados analíticos de oito amostras desse gnaisse, rico em hornblenda e epídoto, estão na tabela 1. Regionalmente, essas rochas variam em composiç̃o de diorítica a granodiorítica (Simões 1984). Petrografica e geoquimicamente, os gnaisses Sanclerlândia são indistintos do de Arenópolis.

As análises isotópicas $\mathrm{Rb}-\mathrm{Sr}$ definiram uma isócrona (MSWD $=1,5$ ) que indica a idade de $940 \pm 150 \mathrm{Ma}$ (Fig. 3). O elevado erro na determinação da idade reflete a restrita variação nos valores de ${ }^{87} \mathrm{Rb}{ }^{80} \mathrm{Sr}(0,11 \mathrm{a} 0,23)$.

A amostra MP-590AA, não computada no cálculo da isócrona, é petrograficamente diferente das amostras restantes, sendo mais rica em homblenda e livre de biotita, podendo representar uma fase plutônica diferente, não-cogenética com as restantes. O baixo valor da razão inicial $(0,7025 \pm$ $0,0004)$ sugere importante contribuição do manto na formação do magma original.

METARRIOLITO DA SEQUENNCIA DE ARENÓPOLIS Análises isotópicas $\mathrm{Rb}-\mathrm{Sr}$, realizadas em seis amostras desse metarriolito (Tab. 2), produziram uma "errócrona" (MSWD $=6,9)$ que indica a idade de $933 \pm 60 \mathrm{Ma}$ e razão ${ }^{87} \mathrm{Sr}{ }^{86} \mathrm{Sr}$ inicial baixa $(0,7035 \pm 0,0003)$ (Fig. 3). A idade obtida é concordante com a idade U-Pb em zircões de $929 \pm 8 \mathrm{Ma}$, reportada por Pimentel et al. (1991).

GRANITO SUBVULCÂNICO (SEQUENNCIA DE JAUPACI) Sete amostras de um pequeno corpo granítico subvulcânico intrudido em rochas metabasálticas da Sequência VulcanoSedimentar de Jaupaci foram analisadas (Tab. 1). No afloramento amostrado, essas rochas encontram-se levemente deformadas e recristalizadas e ainda exibem feições ígneas originais. Fenocristais são de feldspato potássico e quartzo. Hornblenda é o principal componente máfico.

As análises produziram uma isócrona $(\mathrm{MSWD}=1,7)$ que revela a idade de $643 \pm 19$ Ma e razão inicial baixa, igual a $0,7032 \pm 0,0002$ (Fig. 3).

\section{Intrusões graníticas tardi a pós-tectônicas}

Amostras de sete corpos graníticos intrusivos (Granitos Rio Caiapó, Serra do Iran, Israelândia, Serra Negra, Serra do Impertinente, Iporá e dique microgranítico) foram investigadas pelo método $\mathrm{Rb}-\mathrm{Sr}$.

Com a exceção do Granito Rio Caiapó, os granitos estudados mostram caráter pós-tectônico, sendo livres de deformação penetrativa e recristalização. Trata-se de rochas de coloração em geral rósea, eqüigranulares (exceto o Granito Rio Caiapó e a fase precoce do Maciço Granítico da Serra do Impertinente, que são porfiríticos) e têm características geoquímicas gerais comparáveis a granitos do tipo ICaledoniano e do tipo A. Pequenos plutons de composicão gabróica a diorítica são encontrados nas intrusões do Rio Caiapó, Israelândia e Iporá. 
Tabela 1 - Dados isotópicos Rb-Sr para os Gnaisses Arenópolis, Matrinxã e Sanclerlândia e para as rochas metavulcânicas e subvulcânicas de Arenópolis e Jaupaci (* são amostras de metabasaltos)

Table 1 - Rb-Sr isotopic data for the Arenópolis, Matrinxã and Sanclerlândia gneisses, and Arenópolis and Jaupaci metavolcanic and subvolcanic rocks (* are metabasalt samples)

\begin{tabular}{|c|c|c|c|c|}
\hline Amostra & $\mathrm{Rb}(\mathrm{ppm})$ & $\mathrm{Sr}(\mathrm{ppm})$ & ${ }^{87} \mathrm{Rb} /{ }^{86} \mathrm{Sr}$ & ${ }^{87} \mathrm{Sr} /{ }^{86} \mathrm{Sr}$ \\
\hline $\begin{array}{c}\text { Gnaisse Aren6polis } \\
\text { MP-557C } \\
\text { MP-557D } \\
\text { MP-557F } \\
\text { MP-557N } \\
\text { MP-557G } \\
\text { MP-557H } \\
\text { MP-557L } \\
\text { MP-558 } \\
\text { MP-557M } \\
\text { MP-154 } \\
\text { MP-155 }\end{array}$ & $\begin{array}{r}147 \\
126 \\
121 \\
119 \\
115 \\
116 \\
117 \\
32 \\
120 \\
76 \\
110\end{array}$ & $\begin{array}{r}510 \\
650 \\
569 \\
486 \\
566 \\
578 \\
574 \\
932 \\
461 \\
713 \\
1022\end{array}$ & $\begin{array}{l}0,835 \\
0,559 \\
0,617 \\
0,707 \\
0,587 \\
0,578 \\
0,592 \\
0.099 \\
0,756 \\
0,309 \\
0,311\end{array}$ & $\begin{array}{l}0,71398 \\
0,71081 \\
0,71141 \\
0,71246 \\
0,71110 \\
0,71086 \\
0,71108 \\
0,70461 \\
0,71300 \\
0,70717 \\
0,70737\end{array}$ \\
\hline $\begin{array}{l}\text { Gnaisse Matrinxã } \\
\text { VIS-572A } \\
\text { VIS-572C } \\
\text { VIS-572E } \\
\text { VIS-572G } \\
\text { VIS-572H } \\
\text { VIS-572L } \\
\text { VIS-572F } \\
\text { VIS-572J }\end{array}$ & $\begin{array}{l}43 \\
48 \\
60 \\
50 \\
34 \\
45 \\
48 \\
44\end{array}$ & $\begin{array}{r}742 \\
1036 \\
640 \\
673 \\
1211 \\
1150 \\
963 \\
737\end{array}$ & $\begin{array}{l}0,168 \\
0,133 \\
0,269 \\
0,214 \\
0,081 \\
0,113 \\
0,143 \\
0,172\end{array}$ & $\begin{array}{l}0,70477 \\
0,70418 \\
0,70644 \\
0,70493 \\
0,70387 \\
0,70412 \\
0,70450 \\
0,70469\end{array}$ \\
\hline $\begin{array}{r}\text { Gnaisse Sanclerlândia } \\
\text { MP-590AA } \\
\text { MP-590AC } \\
\text { MP-590E } \\
\text { MP-590F } \\
\text { MP-590G } \\
\text { MP-590H } \\
\text { MP-590I } \\
\text { MP-590J }\end{array}$ & $\begin{array}{r}2,5 \\
42 \\
42 \\
27 \\
23 \\
25 \\
30 \\
34\end{array}$ & $\begin{array}{l}821 \\
526 \\
583 \\
587 \\
619 \\
623 \\
531 \\
556\end{array}$ & $\begin{array}{l}0,009 \\
0,231 \\
0,206 \\
0,133 \\
0,108 \\
0,116 \\
0,162 \\
0,175\end{array}$ & $\begin{array}{l}0,70317 \\
0,70547 \\
0,70526 \\
0,70418 \\
0,70390 \\
0,70398 \\
0,70480 \\
0,70482\end{array}$ \\
\hline $\begin{array}{l}\text { Metavulcânicas de Aren } \\
\text { MP-235A } \\
\text { MP-235B } \\
\text { MP-336 } \\
\text { MP-235F } \\
\text { MP-235E } \\
\text { MP-246 } \\
\text { MP-64I* } \\
\text { MP-60C* }\end{array}$ & $\begin{array}{r}4,8 \\
7,0 \\
21 \\
6,3 \\
6,6 \\
14 \\
4,6 \\
4,2\end{array}$ & $\begin{array}{r}145 \\
161 \\
102 \\
192 \\
273 \\
58 \\
103 \\
216\end{array}$ & $\begin{array}{l}0,096 \\
0,126 \\
0,585 \\
0,096 \\
0,071 \\
0,723 \\
0,131 \\
0,058\end{array}$ & $\begin{array}{l}0,70477 \\
0,70541 \\
0,71135 \\
0,70452 \\
0,70460 \\
0,71314 \\
0,70433 \\
0,70368\end{array}$ \\
\hline $\begin{array}{c}\text { Granito Subvulcânico d } \\
\text { VIS-267B } \\
\text { VIS-267F } \\
\text { VIS-267E } \\
\text { VIS-267G } \\
\text { VIS-267J } \\
\text { VIS-267H } \\
\text { VIS-267D }\end{array}$ & $\begin{array}{r}39 \\
120 \\
41 \\
112 \\
109 \\
109 \\
107\end{array}$ & $\begin{array}{l}801 \\
276 \\
841 \\
305 \\
282 \\
281 \\
280 \\
\end{array}$ & $\begin{array}{l}0,142 \\
1,26 \\
0,14 \\
1,06 \\
1,12 \\
1,12 \\
1,10\end{array}$ & $\begin{array}{l}0,70455 \\
0,71447 \\
0,70433 \\
0,71299 \\
0,71346 \\
0,71344 \\
0,71334\end{array}$ \\
\hline
\end{tabular}

GRANITO RIO CAIAPÓ Nove amostras da principal fácies (granito porfirítico portador de homblenda e biotita, levemente deformado e recristalizado) dessa intrusão foram estudadas (Tab. 2). A idade isocrônica $(M S W D=1,4)$ de $587 \pm 17$ Ma (Fig.3) concorda com a obtida por Pimentel \& Fuck (1987b) por intermédio de uma isócrona com quatro pontos ( $585 \pm 12 \mathrm{Ma})$. Entretanto, a razão inicial obtida aqui $(0,7058 \pm 0,0003)$ é consideravelmente mais elevada que o valor previamente publicado $(0,7038 \pm 0,0003)$. Dados usados no cálculo da regressão correspondem a amostras coletadas em uma área restrita na porção central da intrusão, onde o granito é petrograficamente homogéneo. As amostras MP-443 e MP-444 são provenientes da borda oeste do maciço e plotam abaixo da reta de regressão definida, sugerindo que elas não são cogenéticas com o restante das amostras. A margem oeste do granito é caracterizada em vários locais pela abundância de enclaves parcialmente digeridos do Gnaisse Arenópolis encaixante. Assim, é possível que a homogeneidade isotópica de $\mathrm{Sr}$ a nível regional não tenha sido alcançada. 
Uma idade K-Ar de $522 \pm 16$ Ma (Hasui \& Almeida, 1970) reflete resfriamento regional para temperaturas abaixo de $c a .250^{\circ} \mathrm{C}$.

Amostra proveniente de um pequeno pluton gabróico, exposto na parte sudoeste do batólito, também foi analisada (amostra MP-412A). Essa amostra representa a rocha gabróica geoquimicamente menos evoluída $\left(\mathrm{SiO}_{2}\right.$ de $c a$. $50 \%$ ). A análise também plota abaixo da reta de regressão calculada para as rochas de composição granítica, revelando desequilíbrio isotópico entre as fases máficas e félsicas do batólito. A razão ${ }^{87} \mathrm{Sr} /{ }^{86} \mathrm{Sr}$ inicial estimada para o gabro (ca. 0,7035 há $587 \mathrm{Ma}$ ) é consideravelmente menor que a computada para os granitos, o que sugere fontes diferentes (ou diferentes proporções de contaminação crustal) para os magmas parentais dos dois membros finais.

GRANITO SERRA DO IRAN Quatro das 16 amostras investigadas são da fase gabro-diorítica precoce dessa intrusão. As restantes correspondem a biotita granitos (s.s.), que constituem a fase tardia da intrusão. Os resultados analíticos estão na tabela 2 .

As quatro amostras gabro-dioríticas se alinham grosseiramente ao longo de uma regressão que aponta idade aproximada de $620 \mathrm{Ma}$ e razão inicial próxima de 0,704 (Fig. 4).

Tabela 2 -Dados isotopicos Rb-Sr para rochas graniticas do oeste de Goiás (*-gabro-dioritos; 1 -fácies porfirítica precoce, 2 -fácies eqüigranular tardia)

Table 2 - Rb-Sr isotopic data for granites from western Goiás (* - gabbro-diorite; $\mathbf{l}$ - early porphyritic fácies; 2 - late eqüigranular fácies)

\begin{tabular}{|c|c|c|c|c|}
\hline Amostra & $\mathbf{R b}(\mathrm{ppm})$ & Sr(ppm) & ${ }^{87} \mathrm{Rb} /{ }^{86} \mathrm{Sr}$ & ${ }^{87} \mathrm{St} /{ }^{26} \mathrm{Sr}$ \\
\hline \multicolumn{5}{|l|}{ Granito Rio Caiapó } \\
\hline $\mathrm{MP}-461 \mathrm{~A}$ & 134 & 547 & 0,708 & 0,71158 \\
\hline MP-465 & 129 & 228 & 1,640 & 0,71940 \\
\hline MP-443 & 17 & 838 & 0,060 & 0,70510 \\
\hline MP-446 & 126 & 346 & 1,060 & 0,71464 \\
\hline MP-474 & 162 & 270 & 1,730 & 0,72029 \\
\hline MP-444 & 46 & 1036 & 0,128 & 0,70575 \\
\hline MP-445 & 137 & 298 & 1,330 & 0,71705 \\
\hline MP-461C & 135 & 568 & 0,690 & 0,71162 \\
\hline MP-461E & 130 & 455 & 0,826 & 0,71287 \\
\hline MP-412 (gabro) & 20 & 394 & 0,145 & 0,70483 \\
\hline \multicolumn{5}{|l|}{ Granito Serra do Iran } \\
\hline MP-429* & 105 & 560 & 0,541 & 0,70891 \\
\hline MP-428* & 66 & 635 & 0,299 & 0,70657 \\
\hline MP-432A* & 79 & 457 & 0,500 & 0,70812 \\
\hline MP-432B & 83 & 463 & 0,516 & 0,70837 \\
\hline MP-436 & 147 & 50 & 8,510 & 0,77550 \\
\hline MP-439B & 218 & 124 & 5,110 & 0,74738 \\
\hline MP+435B & 195 & 69 & 8,260 & 0,77385 \\
\hline MP-440A & 202 & 131 & 4,480 & 0,74363 \\
\hline MP-433B & 180 & 64 & 8,180 & 0,77074 \\
\hline MP-434 & 205 & 28 & 21,40 & 0,88621 \\
\hline MP-433A & 192 & 63 & 8,870 & 0,77734 \\
\hline MP-440B & 195 & 150 & 3,760 & 0,73770 \\
\hline MP-439A & 211 & 109 & 5,600 & 0,75199 \\
\hline MP-435A & 192 & 89 & 6,300 & 0,75626 \\
\hline MP-442 & 204 & 261 & 2,270 & 0,72286 \\
\hline MP- 430 & 120 & 9 & 40,20 & 1,06919 \\
\hline \multicolumn{5}{|l|}{ Granito Israelândja } \\
\hline MP-529 & 59 & 25 & 6,95 & 0,75954 \\
\hline MP-477A & 123 & 188 & 1,89 & 0,71985 \\
\hline MP-478A & 134 & 150 & 2,58 & 0,72478 \\
\hline MP-522 & 163 & 140 & 3,37 & 0,73190 \\
\hline MP-523 & 121 & 174 & 2,02 & 0,72042 \\
\hline MP-525 & 166 & 133 & 3,64 & 0,73311 \\
\hline MP-527A & 129 & 131 & 2,86 & 0,72690 \\
\hline MP-479 & 165 & 180 & 2,65 & 0,72536 \\
\hline MP-488C & 128 & 151 & 2,46 & 0,72410 \\
\hline MP-521A & 127 & 127 & 2,91 & 0,72697 \\
\hline \multicolumn{5}{|l|}{ Granito Serra do Impertinente } \\
\hline MP-494A & 169 & 43 & 11,4 & 0,79649 \\
\hline MP-495A 1 & 196 & 108 & 5,28 & 0,74600 \\
\hline MP-493B & 193 & 74 & 7,52 & 0,76548 \\
\hline MP-503A & 166 & 169 & 2,85 & 0,72640 \\
\hline MP-506A & 167 & 143 & 3,37 & 0,73142 \\
\hline MP-503B' & 167 & 174 & 2,78 & 0.72596 \\
\hline MP-5072 & 191 & 167 & 3,31 & 0,72934 \\
\hline MP-5012 & 177 & 44 & 11,7 & 0,78831 \\
\hline MP-512A ${ }^{2}$ & 214 & 83 & 7,55 & 0,75864 \\
\hline MP-515A ${ }^{2}$ & 135 & 161 & 2,42 & 0,72377 \\
\hline MP-512B ${ }^{2}$ & 157 & 88 & 5,17 & 0,74212 \\
\hline
\end{tabular}



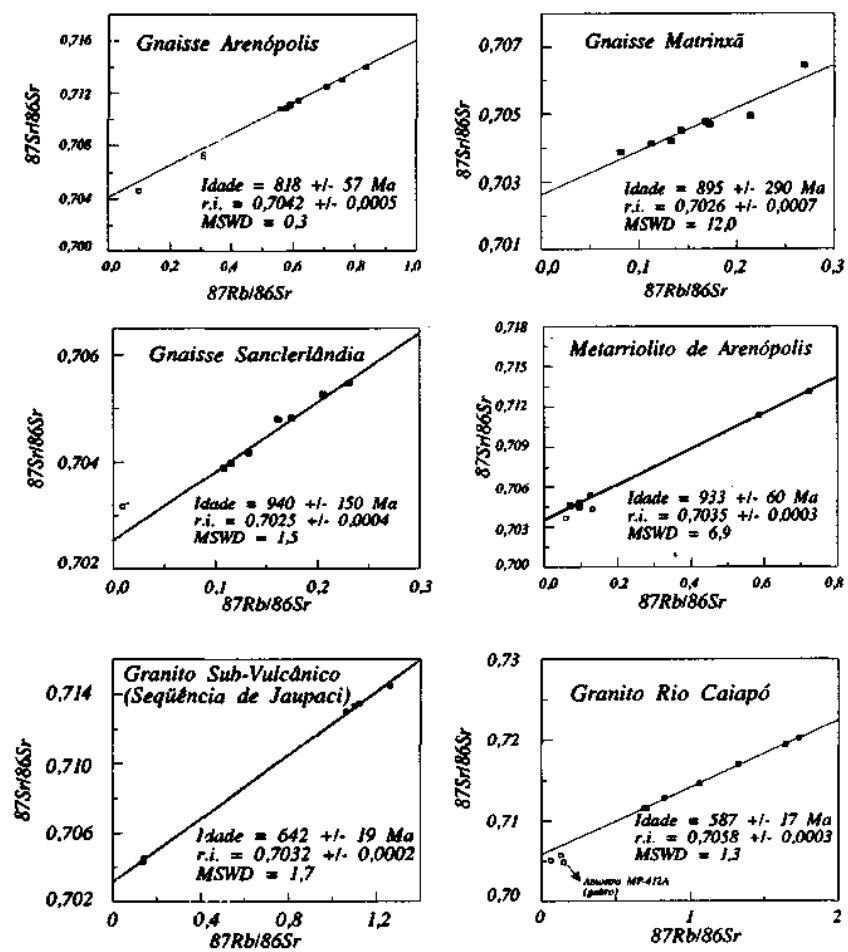

Figura 3 - Diagramas isocrônicos Rb-Sr. Quadrados nãopreenchidos representam pontos analíticos não-incluidos na regressão

Figure $3-\mathrm{Rb}-\mathrm{Sr}$ isochron diagrams. Open squares are analytical points not included in regressions

Onze amostras do granito (s.s.) formam uma "errócrona" $($ MSWD $=8,6)$, com idade de $588 \pm 19$ Ma e razão inicial de $0,7044 \pm 0,0020$ (Fig.4). O mau ajuste dos pontos analíticos à regressão provavelmente deve-se à heterogeneidade isotópica inicial do magma parental, resultando em mistura incompleta das fusões anatéticas. O mesmo é indicado pelas composições isotópicas $\mathrm{Sm}-\mathrm{Nd}$ dessas rochas (dados inéditos de Pimentel 1991). Os valores de $\varepsilon_{\mathrm{Nd}}\left(\mathrm{T}_{\mathrm{DM}}\right)$ dessas rochas variam entre $+2,0$ a $-2,7$, formando uma faixa de variação que é consideravelmente maior que a permitida pêlos erros analíticos unicamente.

GRANITO ISRAELANNDIA Dez amostras do Granito Israelândia foram analisadas (Tab. 2) pelo método $\mathrm{Rb}-\mathrm{Sr}$ e produziram a isócrona (MSWD $=2,5)$ mostrada na figura 4, que indica a idade de $554 \pm 20 \mathrm{Ma}$ e a razão ${ }^{87} \mathrm{Sr} /{ }^{86} \mathrm{Sr}$ inicial de $0,7045 \pm 0,0009$. A idade isocrônica $\mathrm{Rb}$-Sr é algo mais jovem que a idade U-Pb de $579 \pm 3$ Ma obtida para uma fração de esfenos separada desse granito (Pimentel 1991). Casos em que as idades isocrônicas $\mathrm{Rb}$ - $\mathrm{Sr}$ de granitos póstectônicos são até 200 Ma mais jovens que as idades de cristalização indicadas, a partir de dados U-Pb em minerais, são reportadas na literatura (e.g. Beakhouse et al. 1988). A redistribuição do $\mathrm{Sr}$, associada com a alteração deuterica durante o resfriamento da intrusão, é a causa mais provável da discordância. Nesses casos, resultados $\mathrm{Rb}-\mathrm{Sr}$ isocrônicos, apesar de precisos e de apresentar os requisitos necessários que caracterizam uma boa isócrona, podem não carregar significado em termos de cristalização ígnea.

GRANITO SERRA DO IMPERTINENTE Isócronas $\mathrm{Rb}-\mathrm{Sr}$ foram usadas para datar as duas principais fases magmáticas que integram essa intrusão. $\mathrm{O}$ bom ajuste dos pontos às regressões, bem como a larga faixa de variação $\mathrm{Rb} / \mathrm{Sr}$ (Tab. 2) permitiram a determinação de idades relativamente precisas.
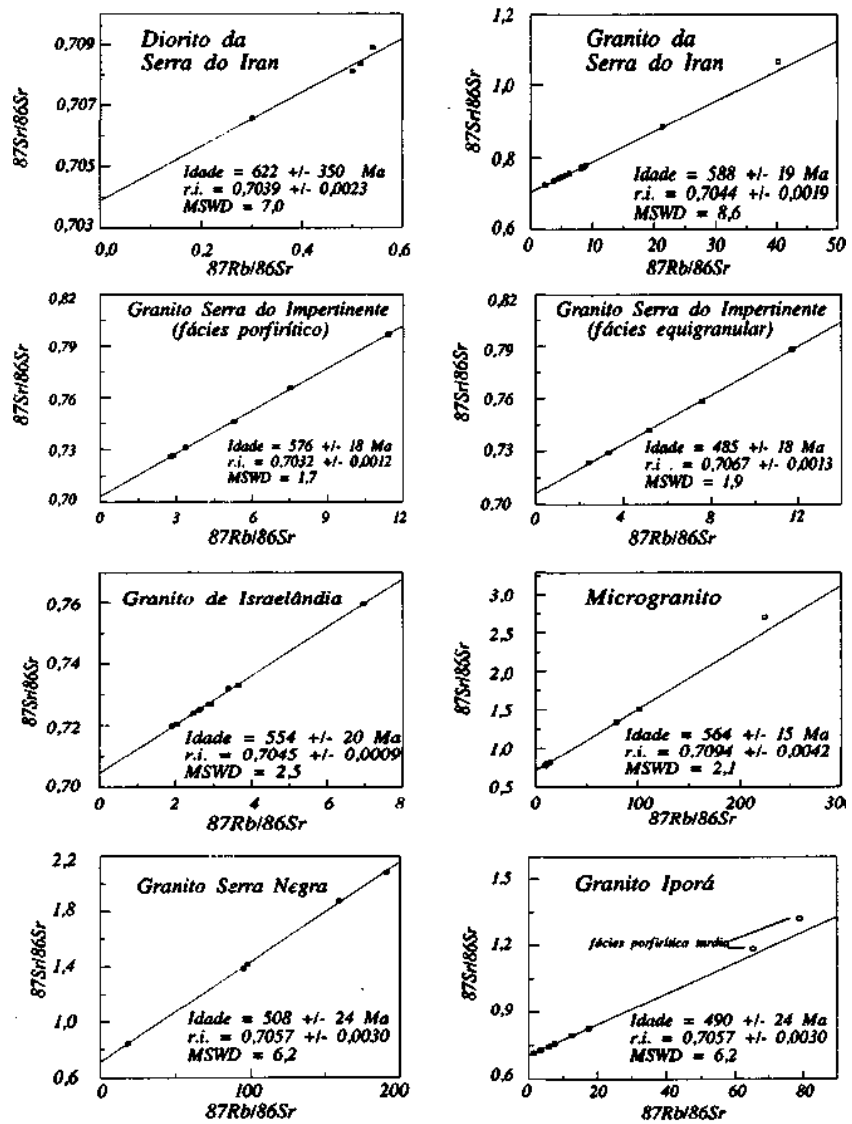

Figura 4 - Diagramas isocrônicos Rb-Sr. Quadrados nãopreenchidos representam pontos analíticos não-incluídos na regressão

Figure 4 - Rb-Sr isochron diagrams. Open squares are analytical points not included in regression

Fácies Porfiritica Precoce Os biotita granitos, que caracterizam essa fase intrusiva, são marcados pela textura porfirítica (megacristais de feldspato potássico), isotrópica e coloração rósea. A isócrona (MSWD $=1,7$ ) obtida para essa fácies indica a idade de $576 \pm 18 \mathrm{Ma}$ e razão ${ }^{87} \mathrm{Sr} /{ }^{80} \mathrm{Sr}$ inicial de $0,7032 \pm 0,0012$ (Fig. 4).

Fácies eqüigranular tardia Biotita granitos que compõem essa fácies mostram característica coloração avermelhada, são eqüigranulares e não-deformados. Resultados isotópicos $\mathrm{Rb}$-Sr produziram isócrona (MSWD = 1,9, Fig. 4) indicando a idade de $485 \pm 18 \mathrm{Ma}$ e razão inicial $(0,7067 \pm$ 0,0013), consideravelmente mais elevada que a da fácies porfirítica. As duas fases representam, portanto, dois episódios magmáticos pós-tectônicos distintos em um mesmo local. A diferença nos valores das razões iniciais das duas fases sugere fontes de características diferentes para os magmas originais.

GRANITO SERRA NEGRA Essa intrusão, exposta oeste da cidade de Piranhas, é caracterizada predominantemente por biotita granitos eqüigranulares de coloração rósea a vermelha, não-deformados. Uma isócrona bem ajustada (MSWD =1,1; Fig. 4) foi obtida com os resultados analíticos de cinco amostras (Tab. 3) e revela a idade de $508 \pm 18$ Ma e razão ${ }^{87} \mathrm{Sr} / *^{6} \mathrm{Sr}$ inicial de $0,710 \pm 0,003$. A razão inicial é mal definida devido aos elevados valores das razões $\mathrm{Rb} / \mathrm{Sr}$. A idade K-Ar de $488 \pm 15 \mathrm{Ma}$, em biotitas desse granito (Hasui \& Almeida 1970), sugere resfriamento relativamente 
rápido da intrusão, o que é compatível com o elevado nível crustal de alojamento do corpo, sugerido pela presença de cavidades miarolíticas e diques pegmatíticos.

GRANITO IPORÁ Análises Rb-Sr de amostras do Granito Iporá (Tab. 3) forneceram uma errócrona (MSWD = $6,0)$ que indica a idade de $490 \pm 24 \mathrm{Ma}$ e razão inicial de $0,7057 \pm 0,0030$ (Fig. 4). As amostras MP-487B e MP487D, representantes de uma fácies tardia, porfirítica, leucocrática e rica em álcalis, não foram incluídas no cálculo da idade.

A amostra MP-546A (Tab.3) corresponde a diorito de um pequeno corpo máfico, na porção noroeste da intrusão. Evidências de campo demonstram contemporaneidade entre os líquidos máficos e félsicos originais. A razão "Sr/^ $\mathrm{Sr}$ inicial estimada para o diorito $(0,7037)$, entretanto, é mais baixa que a computada para as rochas graníticas (s.s.) e provavelmente reflete proporção maior de material derivado de fonte com razão $\mathrm{Rb} / \mathrm{Sr}$ mais baixa.
DIQUE DE MICROGRANITO Seis amostras de dois diques de microgranito, que constituem pequeno enxame de diques cortando rochas metavulcânicas da Sequência de Arenópolis e o granito milonítico da Serra do Tatu, foram analisadas pelo método $\mathrm{Rb}-\mathrm{Sr}$ (Tab. 3). As razões ${ }^{87} \mathrm{Rb} /{ }^{86} \mathrm{Sr}$ são extremamente elevadas, variando entre $c a$. 8,9 e 224. A isócrona (MSWD $=2,5)$, construída com as cinco amostras provenientes de um único dique, indica a idade de $564 \pm 15$ Ma e razão inicial de 0,7094 $\pm 0,0043$ (Fig. 4). A amostra MP-60 pertence a um outro dique e plota acima da regressão.

CONCLUSÕES Os dados geocronológicos aqui apresentados, conjugados com dados $\mathrm{U}-\mathrm{Pb}$ em minerais de Pimentel et al. (1991), revelam dois eventos principais de formação de rochas no oeste de Goiás: (i) entre ca. 940 e 890 $\mathrm{Ma}$, foram formados e adicionados à crosta continental os precursores ígneos dos Gnaisses Arenópolis, Matrinxã e Sanclerlândia e dos metarriolitos da Sequência de Arenópolis; dados isotópicos de $\mathrm{Nd}$, nessas rochas ortognáissicas

Tabela 3 -Dados isotópicos Rb-Sr para rochas graníticas do oeste de Goiás (1 - fácies porfirítica tardia) Table 3 - Rb-Sr isotopic data for granites from western Goiás (1 - late porphyritic fácies)

\begin{tabular}{|c|c|c|c|c|}
\hline Amostra & $\mathrm{Rb}(\mathrm{ppm})$ & $\mathrm{Sr}(\mathrm{ppm})$ & $87 \mathrm{Rb} / 86 \mathrm{Sr}$ & $87 \mathrm{Sr} / 86 \mathrm{Sr}$ \\
\hline $\begin{array}{l}\text { Granito Iporá } \\
\text { MP-546 } \\
\text { MP-552 } \\
\text { MP-481A } \\
\text { MP-542 } \\
\text { MP-551A } \\
\text { MP-541 } \\
\text { MP-544 } \\
\text { MP-487B } \\
\text { MP-487D }\end{array}$ & $\begin{array}{l}161 \\
145 \\
198 \\
294 \\
170 \\
276 \\
208 \\
314 \\
342\end{array}$ & $\begin{array}{r}416 \\
286 \\
77 \\
49 \\
149 \\
64 \\
106 \\
12 \\
16\end{array}$ & $\begin{array}{c}1,12 \\
1,47 \\
7,51 \\
17,4 \\
3,31 \\
12,5 \\
5,72 \\
78,9 \\
65,1\end{array}$ & $\begin{array}{l}0,71157 \\
0,71572 \\
0,75952 \\
0,82501 \\
0,72784 \\
0,79492 \\
0,74544 \\
1,32242 \\
1,18472\end{array}$ \\
\hline $\begin{array}{r}\text { Granito Serra Negra } \\
\text { MP-437A } \\
\text { MP-448D } \\
\text { MP-437E } \\
\text { MP-448E } \\
\text { MP-437B }\end{array}$ & $\begin{array}{l}256 \\
312 \\
365 \\
313 \\
347\end{array}$ & $\begin{array}{r}41 \\
10 \\
7,1 \\
10 \\
6,2\end{array}$ & $\begin{array}{r}18,3 \\
95,1 \\
159 \\
97,8 \\
191\end{array}$ & $\begin{array}{l}0,84466 \\
1,38793 \\
1,87793 \\
1,41844 \\
2,08327\end{array}$ \\
\hline $\begin{array}{r}\text { Microgranito } \\
\text { MP-64C } \\
\text { MP-64G } \\
\text { MP-64E } \\
\text { MP-64B } \\
\text { MP-64D } \\
\text { MP-60 }\end{array}$ & $\begin{array}{l}213 \\
180 \\
448 \\
576 \\
198 \\
947\end{array}$ & $\begin{array}{l}55 \\
59 \\
18 \\
18 \\
40 \\
15\end{array}$ & $\begin{array}{l}11,3 \\
8,86 \\
78,5 \\
101 \\
14,6 \\
224\end{array}$ & $\begin{array}{l}0,80091 \\
0,78151 \\
1,34652 \\
1,51673 \\
0,82462 \\
2,7011\end{array}$ \\
\hline
\end{tabular}

e metavulcânicas, indicam derivação a partir de fontes mantélicas, caracterizando evento de acresção crustal do Neoproterozóico (Pimentel \& Fuck 1992); (ii) entre ca. 590 e $485 \mathrm{Ma}$, foram formadas as intrusões granitóides tardi a pós-tectônicas (Granitos Rio Caiapó, Serra do Iran, Serra do Impertinente, Serra Negra e Iporá e enxame de diques micrograníticos).

A atividade ígnea neoproterozóica não foi restrita aos episódios acima. Dados geocronológicos $\mathrm{Rb}-\mathrm{Sr}$ e U-Pb, para rochas metavulcânicas e subvulcânicas da Sequência de Jaupaci, indica atividade ígnea entre $c a .760$ e $640 \mathrm{Ma}$ naquela área. Dados geocronológicos adicionais são necessários para avaliar a extensão dessa atividade.

Isócronas $\mathrm{Rb}-\mathrm{Sr}$ em rochas miloníticas das áreas de Israelândia-Jaupaci e Fazenda Nova produziram idades de $c a$. 594 e 600 Ma para a recristalização dessas rochas (Pimentel et al. 1991). Tais idades concordam, dentro do erro analítico, com as idades U-Pb em esfeno (ca. 630 e $580 \mathrm{Ma}$ ), que representam, de acordo com Pimentel et al. (1991), idades metamórficas. Essas idades de metamorfismo/recristalização são tipicamente de $c a$. $600 \pm 50 \mathrm{Ma}$, coincidindo grosseiramente com o pico do principal evento tectônicometamórfico do Ciclo Brasiliano no Brasil Central. Esse evento, que causou generalizado reajuste do sistema isotópico $\mathrm{K}$-Ar em minerais, em toda a região no fim do Proterozóico, é caracterizado na região oeste de Goiás pela recristalização de rochas com $>600 \mathrm{Ma}$ de idade e pelo desenvolvimento de zonas de cisalhamento, que são uma das principais feições estruturais do embasamento metamórfico da área.

Os dados apresentados mostram que a resposta do sistema $\mathrm{Rb}-\mathrm{Sr}$ rocha-total, nos ortognaisses e metavulcânicas estudadas, frente o metamorfismo/recristalização ocorrido há $c a$. de $600 \mathrm{Ma}$, varia consideravelmente. No caso do 
Gnaisse Arenópolis, com cerca de $900 \mathrm{Ma}$ de idade, o sistema isotópico $\mathrm{Rb}-\mathrm{Sr}$ "sobreviveu" ao evento metamórfico sofrido por essas rochas há $c a$. $630 \mathrm{Ma}$ (idade U-Pb em esfeno, Pimentel et al. 1991) e indica uma idade de $818 \mathrm{Ma}$. Entretanto, no caso do Metarriolito de Jaupaci (764 Ma, idade U-Pb em zircão), o sistema $\mathrm{Rb}$-Sr rocha-total foi reequilibrado há $c a$. $587 \mathrm{Ma}$. O comportamento diferenciado do sistema $\mathrm{Rb}$-Sr, nos dois exemplos acima, está provavelmente relacionado com a disponibilidade de sítios cristalográficos que acomodam $\mathrm{Sr}$ após o evento de metamorfismo. O Gnaisse Arenópolis é caracterizado por uma mineralogia rica em Ca Plagioclásio cálcico, hornblenda e epídoto abundantes proveram os sítios cristalográficos adequados à acomodação de $\mathrm{Sr}$ produzido em fases minerais de alta razão $\mathrm{Rb} / \mathrm{Sr}$, impedindo a re-homogeneização isotópica em escala maior que a da amostra de mão.
O Metarriolito de Jaupaci, por outro lado, é caracterizado por mineralogia pobre em fases cálcicas, dispondo, portanto, de poucos sítios favoráveis à retenção de $\mathrm{Ca}$ após a recristalização, fato que ocasionaria a perda de $\mathrm{Sr}$ radiogênico do sistema rocha-total e consequente reajuste do sistema isotópico $\mathrm{Rb}-\mathrm{Sr}$.

Após o último evento metamórfico/deformacional, datado em $c a$. de $600 \mathrm{Ma}$, foram alojados os corpos graníticos, os quais apresentaram idades isocrônicas Rb-Sr entre $c a$. 590 e $485 \mathrm{Ma}$, compatíveis com o caráter tardi a pósorogenético do magmatismo. As razões iniciais ${ }^{87} \mathrm{Sr} /{ }^{86} \mathrm{Sr}$ variam entre $c a$. 0,703 e 0,710 e sugerem componentes crustais e mantélicos na origem dos magmas originais.

Agradecimentos Os autores agradecem ao $\mathrm{CNPq}$ e PADCT, pelo apoio financeiro.

\section{REFERÊNCIAS BIBLIOGRÁFICAS}

AMARO, V.E. 1989. Geologia e Petrologia da Sequência Metavulcânica de Jaupaci - GO e Lineamentos Associados. Brasília. 213 p. (Dissertação de Mestrado, IG/UnB).

BEAKHOUSE, G.P.; McNUTT, R.H.; KROGH, T.E. 1988. Comparativo $\mathrm{Rb}-\mathrm{Sr}$ and U-Pb zircon geochronology of late to post-tectonic plutons in the Winnipeg River Belt, Northwestern Ontario, Canada. Chem. Geol, 72:337-351.

FUCK, R.A.; PIMENTEL, M.M.; BOTELHO.N.F. 1987. Granitoid rocks in west-central Brazil: a review. In: INTERN. SYMP. GRANITES AND ASSOCIATED MINERALIZATIONS, 1. Salvador, 1987. Extended Abstracts... Salvador, SGRM. p. 53-59.

HASUI, Y. \& ALMEIDA, F.F.M. 1970. Geocronologia do Centro-Oeste brasileiro. Boi. Soe. Brás. Geol., 19(1):5-26.

MARINI, O.J.; FUCK, R.A.; DARDENNE, M.A.; DANNI, J.C.M. 1984. Província Tocantins. Setores central e sudeste. In: ALMEIDA, F.F.M. \& HASUI, Y. eds. O Pré-Cambriano do Brasil. São Paulo, Edgar Blücher. p. 205-264.

PANKHURST, RJ. \& O'NIONS, R.K. 1973. Determination of Rb/Sr and ${ }^{87} \mathrm{Sr}{ }^{86} \mathrm{Sr}$ ratios of some standard rocks and evaluation of X-ray fluorescence spectrometry in Rb-Sr geochronology. Chem. Geol, 12:127-136.

PIMENTEL, M.M. 1991. Late Proterozoic Crustal Evolution of the Tocantins Province in Central Brazil: an Isotopic and Geochemical Study. England. 248 p. (Ph. D. Thesis, University of Oxford).

PIMENTEL, M.M. \& FUCK, R.A. 1986. Geologia da sequência vulcanosedimentar de Arenópolis (GO). Rev. Brás. Geoc., 16(2):217-223.

PIMENTEL, M.M. \& FUCK, R.A. 1987a. Origem e evolução das rochas metavulcânicas e metaplutônicas da região de Arenópolis (GO). Rev. Brás. Geoc., 17(1):2-14.
PIMENTEL, M.M. \& FUCK, R.A. 1987b. Late Proterozoic granitic magmatism in southwestern Goiás, Brazil. Rev. Brás. Geoc., 17(4):415-425.

PIMENTEL, M.M. \& FUCK, R.A. 1991. Origin of orthogneiss and metavolcanic rock units in western Goiás: Neoproterozoic crustal accretion. Geochim. Brasil., 5(1/2):133-152.

PIMENTEL, M.M. \& FUCK, R.A. 1992. Neoproterozoic crustal accretion in central Brazil. Geology, 20:375-379.

PIMENTEL, M.M.; FUCK, R.A.; CORDANI, U.G.; KAWASHITA, K. 1985. Geocronologia de rochas graníticas e gnáissicas da região de Arenópolis-Piranhas, Goiás. Rev. Brás. Geoc. 15(1):3-8.

PIMENTEL, M.M; HEAMAN, L; FUCK, R.A. 1991. Zircon and sphene U-Pb geochronology of Upper Proterozoic volcanic-arc rock units from southwestern Goiás, central Brazil. J. South Am. Earth Sei., 4:295-305.

SEER, H.J. 1985. Geologia, Deformação e Mineralização de Cobre no Complexo Vulcano-Sedimentar de Bom Jardim de Goiás. Brasília. 230 p. (Dissertação de Mestrado, IG-UnB).

SIMÕES, L.A. 1984. Geologia do Grupo Araxá na Região de Mossâmedes - Goiás e as Ocorrências Minerais Associadas. Brasília, p. 219 p. (Dissertação de Mestrado, IG-UnB).

STEIGER, R.H. \& JÀGER, E. 1977. Subcommision on geochronology convention on the use of decay constants in geo and cosmochronology. Earth Planei Sei. Lett., 36:359-362.

MANUSCRITO A762

Recebido em 9 de junho de 1993

Revisão do autor em 26 de janeiro de 1994 Revisão aceita em 31 demarco de 1994 